\title{
A study to assess the Effectiveness of Autogenic Relaxation on Depression among Menopausal women in rural areas at Thiruvallur district.
}

\author{
Mrs.S.Sujithra, \\ M.Sc(N),M.Sc(Psy),(Ph.d) Lecturer,Saveetha College of Nursing, Thandalam.
}

\begin{abstract}
Women's reproductive events include various stages. Hormonal influence is felt at every stage. These events bring fluctuations in their mood and in some women it causes depression. Researchers had confirmed that hormones have an effect on the brain chemistry which could be an important cause of depression. The present study was undertaken to assess the effectiveness of Autogenic relaxation on depression among Menopausal Women. The study revealed that there was a statistically significant association between the effectiveness of autogenic relaxation on depression among menopausal women in the post experimental group with the type of family at the level of $p<0.05$.
\end{abstract}

Key words: Autogenic relaxation, Depression,Menopausal women,

\section{Introduction:}

World Health Organization (2001) estimated that 450 million people in the world suffer from some form of mental and brain disorders. About 121 million suffer from depression and it is estimated that more than 80,000 die by suicide each year.

American psychiatric association, 2000, stated that depression is a major health problem affecting six to $16 \%$ of Americans. Out of it 10 to $25 \%$ of women and five to $12 \%$ of men experience depression. In addition, depression increases the life time risk of suicide by $2 \%$ to $4 \%$ when compared to the general population, resulting in a $15 \%$ mortality rate.

Menopausal women are most affected because of the changes in the physical and psychological well being. Adding to this, the life events and role changes, which if positive, enhances health and if negative leads to mental disequilibrium.

Emotionally, menopausal women may experience depression, fatigue due to insomnia, hot flashes, night sweats and reduction in self confidence and libido. Although these emotional responses can be triggered by hormonal changes, they may be related to other factors also.

On reaching the menopause, the changes happening in the body, may make a woman feel old, unattractive and worthless. These feelings can trigger depression and lack of sex drive. Relaxation is one crucial way to control these conditions. The investigator realized that autogenic relaxation has been a gift to the menopausal women; it is one of the simplest and easiest forms of relaxation.

So the investigator felt that helping the menopausal women to practice, autogenic relaxation daily, would help them to reduce menopausal depression and enable them to cope up with the menopausal problems.

\section{Review Of Literature:}

Sajatovic. M. et al., (2007), conducted a study regarding menopause among women with depression and schizophrenia. The study concluded that menopause in women causes various health problems which are of major concern. Treatment strategies to resolve problems during menopause among Indian women are least addressed.

Davi. M. et al., (2002), studied the severity and duration of depression in the event of menopause and stated that psychological symptoms during menopause include emotional liability, anxiety, depressed mood, irritability and decreased libido. Severity and duration of symptom findings showed that $50 \%$ of women had severe symptoms of depression. The study concluded that menopausal women need intervention to reduce the symptoms of depression.

Sengupta. T., (2008), conducted a survey on the emergence of the menopause in India and reported that a total of 130 million Indian women are expected to live beyond menopause into old age by 2015 These studies show that menopausal women need lot of social support to relieve the mental stress and depression.

\section{STATEMENT OF THE PROBLEM}

A study to assess the effectiveness of autogenic relaxation on depression among menopausal women in rural areas at Thiruvallur district. 


\section{OBJECTIVES}

1. Assess the level of depression among menopausal women.

2. Elicit the effectiveness of autogenic relaxation on depression.

3. Associate the level of depression with selected demographic variables of menopausal women.

\section{A. RESEARCH DESIGN}

\section{Methodology}

The research design chosen for this study was true experimental in nature.

\section{B. SETTING OF THE STUDY}

The study was conducted among the menopausal women residing in Nemam and Nemam colony at Thiruvallur district.

\section{POPULATION}

Population for this study includes menopausal women with mild and moderate level of depression.

\section{SAMPLE AND SAMPLE SIZE}

Thirty menopausal women in experimental group and thirty menopausal women in control group who fall under the inclusion criteria within the study period were the sample and the sample size was 60 .

\section{E. SAMPLING TECHNIQUE}

The menopausal women were identified in both the groups and the investigator assessed the level of depression by using Cornell dysthymia rating scale. Those who had mild and moderate level of depression and who met the inclusion criteria were randomly selected and assigned for the study using simple random sampling technique by lottery method.

\section{DATA COLLECTION PROCEDURE}

Simple random sampling technique was used by using lottery method. Autogenic relaxation was taught for seven days for the duration of 30 minutes in the morning from 9 am to $1 \mathrm{pm}$. Next day return demonstration was done by the menopausal women and the investigator reinforced them to do every day early in the morning. The post test was conducted after 1 week interval and the same instrument was used to assess the level of depression and results were statistically analyzed.

\section{Results And Findings:}

In control group $12(40.0 \%)$ were in the age group of $41-45$ years, eight $(26.7 \%)$ were in the age group of 51-55 years.

In the experimental group $12(40.0 \%)$ were in the age group of $46-50$ years, eight $(26.7 \%)$ were in the age group of 51-55 years.

The educational status shows that seven $(23.3 \%)$ were illiterates and seven $(23.3 \%)$ had high school education and four $(13.3 \%)$ had primary school education in the control group.

In the experimental group 10(33.3\%) were graduates and four (13.3\%) had high school education.

With regard to the marital status, 26(86.7\%) were married and one (3.3\%) was unmarried and separated in the control group.

As far as occupation is concerned $16(15.3 \%)$ were unskilled laborers and four $(13.3 \%)$ were professionals in the control group.

In the experimental group 14(46.7\%) were house wives and three (10.0\%) were professionals.

When considering economic status $22(73.3 \%)$ were partially dependent and one $(33.3 \%)$ was fully dependent in control group.

In experimental group 17(56.7\%) were partially dependent and one (3.3\%) was fully dependent.

With respect to the no of children, $21(70.0 \%)$ had three or more children and three $(10.0 \%)$ had one child in the control group.

In the experimental group $12(40.0 \%)$ had two children and seven $(23.3 \%)$ had one child. 
According to the type of family, $18(60.0 \%)$ belong to joint family and $12(40.0 \%)$ belong to nuclear family in the control group.

With regard to the period of cessation of menstruation 13(43.3\%) had cessation for three years and three $(10.0 \%)$ had cessation for one year period in control group.

In experimental group 10(33.3\%) had cessation for six months and six (20.0\%) had cessation for 3 years.

The level of depression in control group 10(33.3\%) had mild and 20(66.7\%) had moderate level of depression in the pretest.

In the post test $22(73.3 \%)$ had mild and eight $(26.7 \%)$ had moderate level of depression.

In the experimental group $15(50.0 \%)$ had mild and moderate level of depression in pre test.

In the post test $23(76.7 \%)$ had mild level of depression and seven (23.3\%) had moderate level of depression

\section{FINDINGS:}

1. There is a statistically significant effectiveness of autogenic relaxation on depression among menopausal women in experimental group at the level of $\mathrm{p}<0.05$.

2. There is a statistically significant association between the effectiveness of autogenic relaxation on depression among menopausal women in the post experimental group with the type of family at the level of $\mathrm{p}<0.05$.

Fig:1 MEAN AND SD VALUE ON THE LEVEL OF DEPRESSION DURING PRETEST AND POST TEST AMONG MENOPAUSAL WOMEN IN CONTROL AND EXPERIMENTAL GROUP.

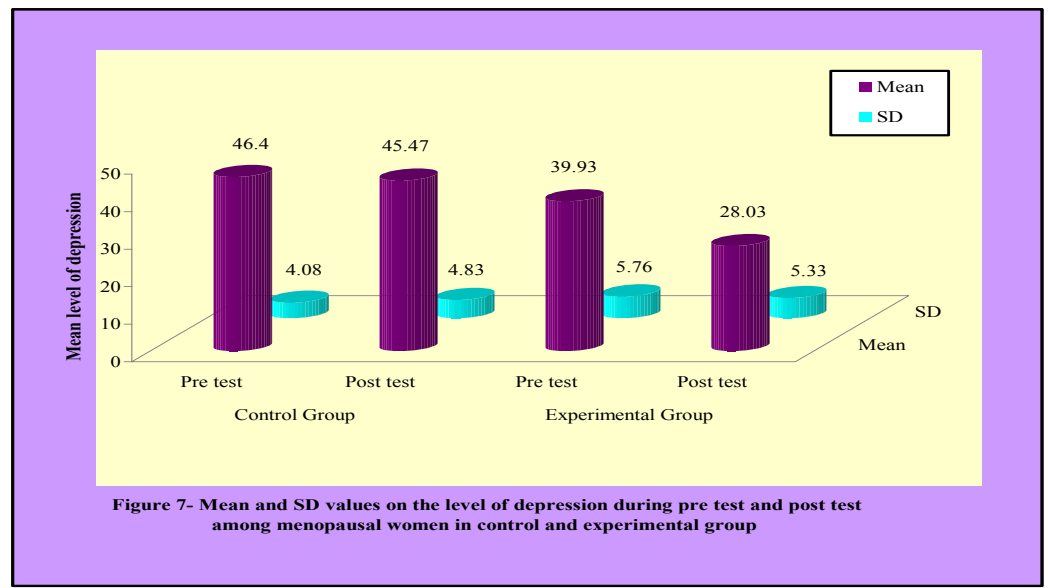

Fig:2 PERCENTAGE DISTRIBUTION OF THE LEVEL OF DEPRESSION AMONG MENOPAUSAL WOMEN IN CONTROL AND EXPERIMENTAL GROUP

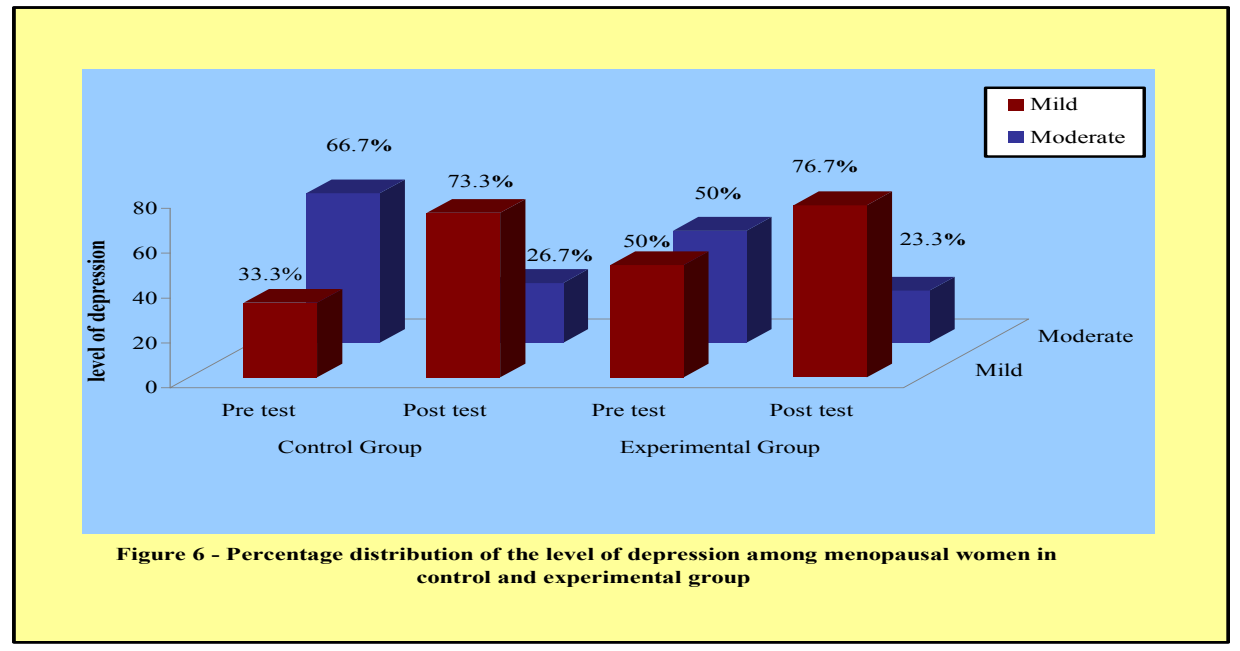




\section{A. NURSING IMPLICATIONS}

In the mental health team, nurses play a vital role in the provision of psychosocial therapies. The nurse knows that the menopausal women suffer from depression and it can be the baseline cause for associated disorders. Hence the autogenic relaxation is a simple exercise and easy way of handling the depression. It can be included as a part of relaxation therapy; therefore this study has important implication in

1. Nursing practice

2. Nursing education

3. Nursing administration

4. Nursing research

\section{Nursing practice}

\section{a. Hospital}

Menopausal women with physical disorders suffer from depression which has not been revealed during hospitalization. The nurse has to assess the level of depression among menopausal women. Autogenic relaxation need to be implemented as a part of other therapies and to be practiced by the nurse in her day-to-day activities. The nurses need to motivate the menopausal women to practice the autogenic relaxation in their daily life.

\section{b. Community}

The nurse who focuses on the rehabilitation of menopausal women should know about the autogenic relaxation. In the family, the members can be encouraged to practice and prevent the maladaptive behavior and also to strengthen their defense mechanism.

Community psychiatric nurse can also formulate interventional programs on autogenic relaxation from adolescents to geriatrics, which will have a cost beneficial effect.

\section{Nursing education}

The concept of health was prevention is better than cure, need to be concentrated among the menopausal women. Autogenic relaxation need to be included as a relaxation therapy in the nursing curriculum. The nursing students need to be educated regarding the autogenic relaxation. Continuing nursing education can be organized on autogenic relaxation.

\section{Nursing administration}

Nursing is an evolving profession to improve the quality of care and practice should be evidence based. The present study showed that there is an effectiveness of autogenic relaxation on depression. The administrator can communicate these findings to the nurses and they can incorporate this in daily patient care. She can motivate nurses to participate in in-service education program on autogenic relaxation.

\section{Nursing research}

Practice emerges from research. Evidence based practice improves the quality of nursing care. This study focuses on improving the quality of nursing care among menopausal women on depression. Research adds value to the comprehensive and holistic care. The nurse involved in patient care can educate the patients and enrich the evidence based care which will enhance the nursing research.

\section{Recommendations For Future Research}

1. Replication of the study could be done with a larger sample to validate and generalize the findings.

2. The study can be done by maximizing the time period of autogenic relaxation.

3. The study can be conducted to determine the effectiveness of autogenic relaxation on specific mental illness.

4. The study can be conducted among different age groups in hospital and community settings.

5. Autogenic relaxation can be applied in novice and senior students of B.Sc Nursing to reduce stress.

6. Comparative study can be done to assess the effectiveness of autogenic relaxation among male and female in general wards.

7. The study can be conducted using various research design.

8. Autogenic relaxation can be applied on the care givers of mentally ill patients to reduce stress. 


\section{References}

[1]. Ahuja ., N. (2002). Depression. A short textbook of psychiatry. (2nd ed.). New Delhi:Jaypee Brothers.

[2]. Ann Rayes. (2000). Diagnostic and statistical manual of mental disorders.(3rd ed.) Washington D.C 55-56

[3]. Andrea ,L. Dunn, O. Chambliss,N. (2005). Exercise treatment for depression. American Journal of preventive medicine, 28(1), 1-7

[4]. Brown .,J.P. and Gallichio .,L. (2009). Menopausal women with depression. Journal of obsterics and gynecology, 17(3), 121-123.

[5]. Bertha celia Salazar., Gonzalea and Mary Jirovce., (2001). Womens perception of exercise and conflicting role responsibilities. International journal of nursing studies. 38(1), 45-49.

[6]. BhargaviDavar., (1995). Mental illness among Indian women. Economic and political weekly.11(2), 28.

[7]. Bennie Rain Gruber., (2003). Gaps in service in the recognition and treatment of depression and suicidal ideation. Perspectives in psychiatric care. 39(4), 151-152.

[8]. Barbara ,B., Signe ,S. (2000). Textbook of Mental health nursing, (5th ed.). Toronto: W.B Saunders.

[9]. Baron ,A. (1995). Textbook of psychology, (3rd ed.). New Delhi: Prentice Hall publishers.

[10]. Chedraui .,A. Guicopabia .,C. (2008). Menopausal women with depression. Journal of Obstetrics and Gynecology, 17(3), $121-123$. 